\title{
Nevus of Ito
}

National Cancer Institute

\section{Source}

National Cancer Institute. Nevus of Ito. NCI Thesaurus. Code C7582.

A large brown, blue, or gray hamartoma of dermal melanocytes, usually on the shoulder and upper arm that is most commonly found in Asian populations and in females. It is sometimes associated with sensory changes in the involved skin area, but very rarely becomes cancerous. 